\title{
A relação entre redes e turismo: uma análise bibliométrica sobre a emergência de um novo paradigma no planejamento turístico
}

\section{The relationship between networks and tourism: a bibliometric analysis about the emergence of a new paradigm in tourism planning}

\author{
Thiago Reis Xavier (XAVIER, T. R.) \\ Raoni de Oliveira Inácio (INÁCIO, R. de O.) *** \\ Milton Luiz Wittmann (WITTMANN, M. L.) \\ Angela Cabral Flecha (FLECHA, A. C.)
}

\begin{abstract}
RESUMO - O turismo constitui um setor fragmentado, multifacetado e sua composição é em quase todos os segmentos por pequenas e médias empresas (PME's) prestadoras dos mais variados tipos de serviços. A falta de um planejamento compartilhado entre as empresas do setor turístico e a necessidade por dados que subsidiem as tomadas de decisão a empresários e aos governos locais têm levado ao enfraquecimento do poder competitivo de destinos. Os aglomerados (clusters) aparecem como uma alternativa de promoção do desenvolvimento regional. Este artigo tem como objetivo ressaltar, através da relação entre os conceitos de redes, redes de PME's e o turismo, como o entendimento das relações entre os atores de um destino pode proporcionar sua qualificação da oferta turística. Ademais, procura-se verificar como está a produção acadêmica sobre o tema em epígrafe. Tal objetivo pôde ser alcançado por meio de uma revisão teórica e aplicação da bibliometria na ISI Web of Science do índice de citações ISI Citation Indexes.
\end{abstract}

Palavras chave: Turismo; Redes; Bibliometria.

ABSTRACT - Tourism is a fragmented and multifaceted sector. It is consisted in almost all segments of small and medium enterprises (SMEs), which provide the most varied services types. The lack of a shared planning among the companies in the tourism sector and the need for data that support the decisions of businessmen and local government has led to the weakening of the competitive power of destinations. So, clusters appear as an alternative of regional development promotion. The aim of this article is to show a relation among the concepts of networks, networks of SMEs and tourism, and how the understanding of relations among the actors of a destination can provide local tourism qualification. So it also tried to identify how the academic production is on this subject. This goal could be achieved through a theoretical review and application of bibliometrics technique in ISI Web of Science in the citation index ISI Citation Indexes.

Keywords: Tourism; Networks; Bibliometry.

\footnotetext{
" Graduação em Turismo (Bacharelado) pela Universidade Federal de Ouro Preto - UFOP. Mestrado e doutorando do Programa de Pós-graduação em Administração da Universidade Federal de Santa Maria - UFSM, na linha de pesquisa: Estratégia e Inovação. Bolsista CAPES/REUNI. Endereço para correspondência: Rua Floriano Peixoto, 1130 - ap. 151. CEP: 97015-371 - Santa Maria - RS (Brasil). E-mail: thianaka@ yahoo.com.br

** Graduação em Turismo (Bacharelado) pela UFOP. Mestrando do Programa de Pós-graduação em Administração da UFSM, na linha de pesquisa: Estratégia e Inovação. Bolsista CAPES/DS. Endereço para correspondência: Rua João XXIII, 78. CEP: 35400-000 - Ouro Preto - MG (Brasil). E-mail: raoni06@ yahoo.com.br

*** Graduação em Engenharia pela Universidade Federal do Rio Grande do Sul (UFRGS) e Administração pela Universidade Regional do Noroeste do Estado do Rio Grande do Sul - UNIJUÍ. Mestrado em Administração pela UFRGS. Doutorado em Administração pela Faculdade de Economia, Administração e Contabilidade da Universidade de São Paulo - FEA/USP. Professor Associado IV da UFMS. Endereço para correspondência: Rua Duque de Caxias 2400 - ap. 201. CEP: 97060-210 - Santa Maria - RS (Brasil). E-mail: wittmann@ profwittmann.com

***** Graduação em Turismo pela Faculdade de Turismo de Belo Horizonte e em Comércio Exterior pelo Centro Universitário de Ciências Gerenciais UNA. Especialização em Planejamento do Desenvolvimento Turístico pelo Centro Interamericano de Turismo - CENID. Mestrado em Engenharia de Produção pela Universidade Federal de Santa Catarina - UFSC e Doutorado em Engenharia de Produção pela Universidade Paulista - UNIP. Professora adjunto da UFOP. Endereço para correspondência. Universidade Federal de Ouro Preto, Departamento de Turismo, campus do Morro do Cruzeiro. CEP: 35400-000 - Ouro Preto - MG (Brasil). E-mail: angelflecha@gmail.com
} 


\section{INTRODUÇÃO}

Ao longo dos anos, as regiões e cidades, no Brasil, se tornaram centros de referência, atraindo, anualmente, visitantes de diversos lugares, fazendo do turismo uma das suas principais atividades econômicas. Entretanto, na maioria dos casos, a atividade continua se desenvolvendo de forma espontânea e desordenada, sem um planejamento adequado. Esta espontaneidade, até a poucos anos, promoveu o desenvolvimento de relacionamentos e critérios nas cidades turísticas que, na maioria das situações, necessita de coordenação (FLECHA, 2010).

Corroborando com tal visão, Xavier et al. (2011) e Inácio et al. (2012) ressaltam que, pela falta de coordenação, o turismo constitui um setor fragmentado, multifacetado e sua composição é formada em quase todos os segmentos por pequenas e médias empresas (PME's) prestadoras dos mais variados tipos de serviços.

Verifica-se que a falta de um planejamento compartilhado entre as empresas do setor turístico e a necessidade por dados que subsidiem as tomadas de decisão a empresários e aos governos locais podem levar ao enfraquecimento do poder competitivo de destinos brasileiros. Fato que pode acarretar um menor volume de arrecadação de receitas e conseqüentemente menor movimento econômico do segmento turístico (XAVIER et al., 2011).

A título de exemplificação argumenta-se que o enfraquecimento da atividade turística pode estimular investimentos na reestruturação de políticas de planejamento que visam qualificar a oferta turística de um local (FLECHA, 2010). Nesta realidade, os aglomerados de empresas aparecem como alternativa de promoção do desenvolvimento regional de cidades turísticas, que podem passar a se constituir em Distritos Industriais (DI), Arranjos Produtivos Locais (APLs) e ou Sistemas Locais de Produção e Inovação (SLP\&I), conforme (MARTINS et al., 2009). Estas abordagens apresentam características próprias pela formação de alianças estratégicas, que se caracterizam por acordos formais e informais entre empresas que permitem o intercâmbio de informações e a aglutinação de competências (MARTELETO; DE OLIVEIRA E SILVA, 2004).

Nota-se este fenômeno do agrupamento nos diferentes setores de serviço, comércio e indústria como forma de aumentar a competitividade. A partir desta premissa, advêm os seguintes questionamentos balizadores do presente estudo: o que 
um agrupamento pode trazer de benefícios para o turismo? Quais são suas características? Qual a sua relação com turismo?

O estudo da relação redes e turismo representa um campo ainda pouco explorado pelos pesquisadores. No entanto, Castells (2000), Capra (2001), Martinho (2003), Bernardes et al. (2006) e Lazzarini (2008) apresentam importantes estudos sobre redes; e Oliveira (2000), Beni (2001), Cooper et al. (2001), Goeldner et al. (2002), Chon (2003), Novelli et al. (2006), Wang e Fesenmaie (2007), Flecha (2010), Inácio et al. (2012) e Xavier et al. (2011) fornecem importantes considerações sobre turismo, o que possibilita estabelecer uma correlação entre os dois temas.

As redes são representadas nos mais diversos e diferentes sistemas. Nas redes celulares, nas redes neurais, nas redes organizacionais, como também, nas redes sociais, nas redes de empresas, dentre outras. No cotidiano pode-se notar a presença das redes nas cadeias de lojas, bancos, lanchonetes e supermercados; ou em outros serviços, tais como: no transporte, nas telecomunicações, internet, e assim por diante (MARTINHO, 2003). Da mesma forma, no setor de turismo, pelo fato de agregar diferentes atividades, há a necessidade de compartilhamento de ações e atividades que se complementam na oferta de distintos serviços ao usuário.

Com base nos preceitos apresentados, este artigo tem como objetivo estabelecer, por meio de revisão bibliográfica, uma relação entre os conceitos de redes, cooperação e redes de PME's e o turismo, procurando ressaltar como o entendimento das relações entre os atores de um mesmo destino pode proporcionar sua qualificação da oferta turística além de verificar como está a produção acadêmica sobre o tema em epígrafe.

\section{REDES}

Redes, durante quase todo o tempo, são estruturas invisíveis e informais. Contudo, as mesmas são percebidas somente quando as pessoas precisam delas, ou seja, quando elas são acionadas (RUIZ et al., 2005). A figura da rede é usada para designar ou qualificar sistemas, estruturas ou desenhos organizacionais compostos por indivíduos, grupos, organizações conectados por algum tipo de relação (MARTELETO; DE OLIVEIRA E SILVA, 2004; LAZZARINI, 2008). 
Conforme Castells (2000, p. 498) as redes podem ser definidas como "estruturas abertas capazes de expandir de forma ilimitada, integrando novos nós desde que consigam comunicar-se dentro da rede", o que as caracterizam como um sistema aberto altamente dinâmico e suscetível à inovação. Abertas e democráticas, as redes proporcionam a identidade de seus membros, sem, no entanto, anular a sua diversidade, não impedindo que, a qualquer instante, novos atores possam integrar-se (RUIZ et al., 2005).

Permitindo ampliar a visão sobre a estrutura das redes, Capra (2001, p. 44) defende que "desde que os sistemas vivos, em todos os níveis, são redes, devemos visualizar a teia da vida como sistemas vivos (redes) interagindo à maneira de redes com outros sistemas (redes)". O autor complementa seu pensamento relatando que, na natureza, não há 'acima' ou 'abaixo', não havendo hierarquias.

Ressaltando a propriedade não hierárquica das redes, Martinho (2003) destaca que uma estrutura em rede se forma a partir da conectividade entre seus pontos ou nós, baseada na capacidade e dinâmica produzida por esse tipo de sistema, que são: não linearidade (a rede se estende em todas as direções); laço de realimentação (as mensagens viajam ao longo de um caminho cíclico); capacidade de regular a si mesma (capacidade de corrigir seus erros e organizar a si mesma); multiplicação de ações (poder de expansão das conexões); dinâmica do relacionamento horizontal (ausência de uma relação de subordinação); e interdisciplinaridade (ancorados em perspectivas filiadas às várias correntes do chamado pensamento sistêmico e às teorias da complexidade).

Bernardes et al. (2006) destacam a participação voluntária como a primeira précondição para a existência de uma rede. A autonomia é o fundamento do modo de operação dos integrantes, pois sem a participação ativa nenhuma iniciativa vai adiante. As redes decorrem de uma relação moral de confiança, sendo um grupo de agentes individuais que têm em comum normas ou valores além daqueles necessários às transações habituais de mercado (FUKUYAMA, 2000).

Os autores Marteleto e De Oliveira e Silva (2004) analisam as redes no contexto social, cuja estrutura de cooperação funciona como um tecido que condiciona a ação dos indivíduos nela inseridos. Os mesmos evidenciam as relações sociais dos indivíduos como um elemento chave para a compreensão da sociedade, criticando o conceito de 
indivíduo (ser humano vivendo isoladamente) e o conceito de sociedade (entendida simplesmente como um conjunto de indivíduos). Bauman (2001) ratifica essa dinâmica social proporcionada pelas redes, quando suas ações são realizadas independentemente da vontade de seus componentes isolados, e sim sociais, fazendo das redes um ambiente socialmente compartilhado.

A compreensão do conceito de redes torna possível observar a superação do trabalho fragmentado (divisão do trabalho), característica marcante da era industrial, por um modelo de produção mais interativo (sistêmico) característico da era pós-industrial. Este modelo possibilitou desenvolver uma correlação entre os conceitos apresentados com a evolução nas formas de administrar as organizações (FUKUYAMA, 2000). No mundo contemporâneo, para serem competitivas, as organizações se constituem em modelos sistêmicos, que investem em tecnologias de produção, de processos, de informação e de gestão, sendo representadas por sistemas abertos e fechados, em constantes interações com o ambiente (CAPRA, 2001), a exemplo das alianças estratégicas.

\subsection{TIPOS DE ALIANÇAS ESTRATÉGICAS}

Para que se possa realizar uma exploração aprofundada acerca das relações existentes entre as redes e sua aplicabilidade no turismo, faz-se necessário conhecer os tipos de alianças estratégicas entre empresas. Tais arranjos, por meio da cooperação entre seus atores e do compartilhamento de informações, estabelecem relações que estimulam a ampliação de possibilidades do desenvolvimento do turismo.

Destacados tais aspectos, na presente seção são apresentadas algumas conceituações e diferentes formas através das quais o conceito de redes é utilizado como uma estratégia dentro do ambiente empresarial, além dos benefícios que esses tipos de alianças podem trazer.

O interesse pelo estudo das redes no ambiente das empresas tem origem a partir da década de 70, aliado à emergência de um novo paradigma tecnológico, observado pelo surgimento de aglomerações, tanto em indústrias tradicionais, como a dos móveis na Dinamarca, a têxtil na Itália e a de confecções em Taiwan e na Tailândia, quanto em indústrias modernas, como a microeletrônica no Silicon Valley, nos EUA (SANTOS; 
CROCCO; SIMÕES, 2003). Ressaltando os casos citados, os autores em epígrafe argumentam que a proximidade física das PME's propiciava não somente externalidades, mas também condições para uma interação cooperativa no sentido da superação de problemas comuns.

Quando aglomeradas, as PME's se beneficiam de economias externas locais, como: "relações sociais favoráveis à cooperação, utilização de mão-de-obra local especializada, o reforço da identidade da região, a atração de compradores internacionais, maior poder de barganha frente a entidades de apoio" - (sindicatos, governo, universidades, associações de classe, bancos), entre outras (OLIVEIRA; TORKOMIAN, 2005, p. 94).

Pode-se descrever aglomerações produtivas e distritos industriais como arranjos produtivos nos quais alguns aspectos, em maior ou menor escala, se fazem presentes: a) forte cooperação entre os agentes; b) identidade sociocultural; c) ambiente institucional; d) atmosfera industrial; e) apoio das autoridades locais; f) existência de instituições de coordenação; g) índice de sobrevivência de empresas elevado; h) dinamismo e competitividade industrial; i) fatores locacionais favoráveis (recursos naturais, recursos humanos, logística, infraestrutura); e j) fortes ligações econômicas entre os agentes (SANTOS; CROCCO; SIMÕES, 2003).

Cardoso e Pussiareli (2006, p. 2) definem os distritos industriais como aglomerados de "agentes econômicos, políticos e sociais, localizados em um mesmo território, que apresentam, real ou potencialmente, vínculos consistentes de articulação, interação, cooperação e aprendizagem".

Um arranjo produtivo local compreende um recorte do espaço geográfico (parte de um município, conjunto de municípios, bacias hidrográficas, vales e serras) que possua sinais de identidade coletiva (sociais, culturais, econômicos, políticos, ambientais ou históricos). Outras características importantes é que os aglomerados devem manter ou promover a interação entre os atores, estabelecer parcerias e compromissos visando manter e especializar os investimentos de cada um no território, e promover uma integração econômica e social no âmbito local (CARDOSO; PUSSIARELI, 2006, p. 3).

Outra tipologia de aglomerados que podem ser ponderados são os dos clusters. Estas aglomerações são definidas como "conjunto de organizações e instituições 
concentradas geograficamente em torno de um ou mais setores industriais" (MARTELETO; DE OLIVEIRA E SILVA, 2004, p. 47), que possuem canais comuns de comercialização, diálogos e comunicação (NOVELLI et al., 2006).

Porter (1999) reforça a teoria salientando que um cluster só pode ser entendido, de modo abrangente, como concentração setorial e geográfica de empresas - os clusters são formados apenas quando os aspectos setorial e geográfico estão concentrados. Num cluster encontra-se um amplo escopo para a divisão de tarefas entre empresas, bem como para a especialização e para a inovação, elementos essenciais para a competição além de mercados locais, que geralmente são formados por PME's.

As PME's serão as grandes beneficiadas pelos clusters como uma forma de acesso a novos mercados e aprimoramento das relações com instituições e bens públicos. Um cluster poderá dispor de profissionais mais capacitados e melhorias de fluxo de informação, usufruindo do posicionamento geográfico e setorial como forma de ganho de eficiência coletiva. É possível encontrar num cluster um amplo escopo para a divisão de tarefas entre empresas, bem como para a especialização e para a inovação elementos essenciais para a competição além de mercados locais (WITTMANN et al., 2004). Percebe-se, igualmente, acesso a conhecimentos, velocidade de comunicação através de canais locais, redução de custos de produção, e produtos e serviços mais acessíveis economicamente (NOVELLI et al., 2006) como sendo algumas das vantagens competitivas que se pode obter pela participação em clusters.

Humphrey e Schmitz (1998) focam na eficiência coletiva de um cluster e ressaltam que os benefícios pela formação de um cluster só podem ser obtidos via um conjunto de fatores facilitadores, os quais representam o conceito de eficiência coletiva, a saber: 1) Divisão do trabalho e da especialização entre produtores; 2) Estipulação da especialidade de cada produtor; 3) Surgimento de fornecedores de matérias primas e de máquinas; 4) Surgimento de agentes que vendam para mercados distantes; 5) Surgimento de empresas especialistas em serviços tecnológicos, financeiros e contábeis; 6) Surgimento de uma classe de trabalhadores assalariados com qualificações e habilidades específicas; 7) Surgimento de associações para a realização de lobby e de tarefas específicas para o conjunto de seus membros.

Marteleto e De Oliveira e Silva (2004) destacam que para se entender a relevância dos clusters de empresas para o processo de desenvolvimento é necessário 
que exista uma investigação dos processos geradores de conhecimento nas empresas e nos processos interativos empresas/instituições e suas capacidades de inovação, como também, a compreensão - pelas empresas e organizações (governo, universidades e institutos de pesquisa) - da relação existente entre firmas e empresários nos clusters. Um cluster deve se manter vinculado ao mercado, como também, fazer ligações com as organizações de Pesquisa e Desenvolvimento (P\&D) e instituições acadêmicas (NOVELLI et al., 2006).

\section{COOPERAÇÃO E REDES DE PME'S}

A quebra de paradigma acontecida a partir da segunda metade do século XX, quando ocorreu a passagem da era industrial para a era pós-industrial, fez surgir a "sociedade da informação", na qual os serviços passam a substituir a fabricação como fonte de riqueza, o intelectual assume um papel de maior importância em relação ao trabalho braçal e a produção passa a ocorrer de forma globalizada (FUKUYAMA, 2000), quando surge a necessidade por sistemas flexíveis e dinâmicos de produção, funcionando cada vez mais integrados entre si (CAPRA, 2001).

As transformações técnicas, organizacionais e econômicas ocorridas durante a era pós-industrial criaram novas relações entre empresas, entre empresas e trabalhadores e entre empresas e instituições, provocando alterações na forma de produzir, de administrar e de distribuir (WITTMANN; VENTURINI; SCHMITT, 2004).

Trata-se de um momento de transição, no qual cabe ressaltar: a) o intenso ritmo das mudanças tecnológicas que acelera a obsolescência técnica de equipamentos, processos e produtos; b) as crescentes flutuações dos mercados; c) a diluição de suas fronteiras e o aumento das condições de incerteza e de risco em que devem ser tomadas as decisões dos agentes econômicos; d) as empresas em muitos países defrontam-se com crescentes tensões nas áreas políticas, trabalhistas e de legislação (DE SOUZA, 1993); o que evidencia a associação em rede como uma alternativa para as PME's, na qual aqueles, antes concorrentes, se juntam estabelecendo uma interação com fornecedores, prestadores de serviços, clientes e know-how (ZAGO et al., 2007). 
Ao incorporar tecnologias de ponta aos seus processos produtivos, modificar sua estrutura organizacional e estabelecer novas relações com o ambiente socioeconômico, as PME's podem aumentar seu poder de competição com as grandes empresas (OLAVE; AMATO NETO, 2005).

Redes se referem a arranjos interorganizacionais baseados em vínculos sistemáticos, muitas vezes de caráter cooperativo entre empresas formalmente independentes, que dão origem a uma forma particular de coordenação das atividades econômicas (HASENCLEVER et al. 2002, p. 347).

O recorte analítico do conceito de redes de empresas pode estar relacionado a alguns elementos morfológicos genéricos tais como nós (unidades básicas da empresa a ser pesquisada), posições (estrutura da divisão do trabalho), ligações (relacionamentos entre as empresas) e fluxos (de bens e informações) (GUERRINI, 2005). Esses trazem a necessidade pelo conhecimento das dinâmicas de coordenação e integração de cada ator envolvido em cada processo, conforme faz Fusco et al. (2005), que se baseiam no conceito de redes simultâneas (física, de valor, de negócio) e subsidiam esta análise nos seguintes conceitos:

- "Rede física": transporta insumos de fornecedores aos locais de produção, produz fisicamente produtos e movimenta os materiais em processo - desempenhando atividades de estocagem e distribuição entre os clientes finais;

- "Rede de valor": diretamente relacionada ao conceito de cadeia de valor, é responsável por identificar o valor do produto para os consumidores finais, que pode ser: preços menores, venda de produtos diferenciados aos clientes de uma empresa ou oferecendo benefício único (especial);

- "Rede de negócio": possibilita às empresas alcançar objetivos que não se pode alcançar independentemente através do fluxo de informações e partilha de recursos, conhecimentos e experiência.

Redes configuram diversos tipos de alianças entre as PME's como as redes flexíveis, os clusters (agrupamentos), as organizações virtuais, ou as chamadas "supply chain management" ou gerenciamento da cadeia de suprimentos (XAVIER et al., 2011; INÁCIO et al., 2012). Além desses, Olave e Amato Neto (2005) ainda destacam outros tipos de alianças estratégicas, conforme se apresenta no quadro 1: 
QUADRO 1 - TIPOS DE ALIANÇAS ESTRATÉGICAS

Tipo de aliança $\quad$ Descrição

a) Alianças Multi-

organizacionais de Serviços ou

Consórcios

b) Alianças Oportunísticas ou Joint-venture

c) Alianças de Parceria entre Fornecedores, Consumidores e Funcionários
Organizações (empresas) que tenham uma necessidade similar (frequentemente empresas de um mesmo setor industrial) juntamse para criar uma nova entidade que venha a preencher aquela necessidade delas todas.

As organizações vêm uma oportunidade para obter algum tipo de vantagem competitiva imediata (ainda que temporária), por meio de uma aliança que as leve para a constituição de um novo negócio ou para a ampliação de algum já existente.

Neste tipo de aliança há o envolvimento de vários parceiros (stakeholders) no processo de negócio (business process) em seus diferentes estágios de criação de valor - fornecedores, seus clientes e seus funcionários.

FONTE: ELABORADO PELOS AUTORES, A PARTIR DE OLAVE E AMATO NETO (2005).

Por meio do quadro 1, pode-se perceber que embora se observem simetrias nos objetivos das organizações envolvidas em processos de alianças, notam-se características particulares inerentes a cada tipo de estratégia.

Nestes preceitos, considera-se que as alianças multi-organizacionais de serviços (ou consórcios) ocorrem entre empresas do mesmo setor, que se unem para criar uma nova entidade capaz de atender às necessidades de todas as envolvidas. Por outro lado, as empresas que participam de alianças oportunísticas (ou joint-ventures) visam obter uma vantagem competitiva imediata. Enquanto as parcerias entre fornecedores, consumidores e funcionários trazem para as envolvidas uma possibilidade de criação de valor (OLAVE; AMATO NETO, 2005).

As alianças empresariais surgem como uma forma de acesso a tecnologias e redução dos custos de transação relativos ao processo de inovação (GUERRINI, 2005), sendo uma alternativa da organização para se otimizar as operações (eficiência) ou atender melhor a necessidades ditadas pelo contexto concorrencial (eficácia) (FUSCO et $a l ., 2005)$.

Desenvolvendo alianças estratégicas em rede, as empresas complementam-se umas às outras nos planos técnicos (meios produtivos) e comerciais (redes de distribuição), podendo se traduzir, também, pela criação de uma central de compras comum (OLAVE; AMATO NETO, 2005), o que possibilita aos seus atores, oferecerem maiores vantagens em termos de flexibilidade de atendimento a pedidos diferenciados, agregando valor ao serviço (GUERRINI, 2005); reduzindo custos relativos ao processo de inovação; aumentando a eficiência econômica e a competitividade; minimizando 
incertezas e riscos e obtendo benefícios em relação a custos, preços e prazos junto aos fornecedores (ZAGO et al., 2007).

Fusco et al. (2005) mencionam algumas características de uma rede de empresas ressaltando aspectos como a não-hierarquia, o compromisso de aliança a longo prazo, a flexibilidade e a colaboração, salientando que a rede pode variar quanto ao tamanho, objetivo e estrutura (formal e informal).

\section{TURISMO}

Composto por inúmeros agentes, tais como: órgãos reguladores, empresas e associações, o fenômeno do turismo representa uma atividade em crescimento devido sua importância e significado para o desenvolvimento regional criando empregos (GOELDNER; RITCHIE; McINTOSH, 2002). Esse cria empregos, promove a entrada de divisas, aumenta a arrecadação de impostos, desenvolve o setor industrial e de serviços (OMT, 2001) e, por conseguinte, ocasionando impactos econômicos, sociais e ambientais (COOPER et al., 2001).

Contudo, devido a sua complexidade, ainda não existe unanimidade de aceitação no que diz respeito à conceituação do turismo, o que leva vários autores como Beni (2001); Cooper et al. (2001); Goeldner, Ritchie e McIntosh (2002); Oliveira (2000) e OMT (2001) a abordarem o tema. Dentre as várias conceituações existentes, Cooper et al. (2001, p. 40) definem turismo como "gama de indivíduos, empresas, organizações e lugares, que se combinam de alguma forma para proporcionar uma experiência de viagem”. Goeldner, Ritchie e McIntosh (2002, p. 23) complementam essa definição ao conceituar o turismo como "soma de fenômenos e relações originadas da interação de turistas, empresas, governos locais e comunidades anfitriãs, no processo de atrair e receber turistas e outros viajantes".

De forma complementar a essas definições sobre o turismo, Beni (2001, p. 37) classifica a atividade turística como um "elaborado e complexo processo de decisão sobre o que visitar, onde, como e a que preço". Segundo o referido autor, esse processo de decisão engloba diversos aspectos, tais como: fatores de realização e social, natureza 
motivacional, econômica, cultural, ecológica e cientifica que ditam a escolha dos destinos, a permanência, os meios de transporte e o alojamento.

A OMT (2001) aponta alguns elementos comuns a todas as definições: movimento de turistas para fora da residência; realização de atividades não permanentes no local; compreende tanto a viagem e quanto as atividades realizadas; e inclui serviços e produtos voltados à satisfação do turista; destacando, também, o papel do espaço geográfico e dos operadores como elementos pertencentes ao turismo, o que levou Goeldner et al. (2002, p. 29) a fazer a seguinte colocação:

[...] a abordagem do turismo pelo geógrafo trata da localização de áreas turísticas, dos deslocamentos de pessoas em função das localidades turísticas, das mudanças que a atividade traz para a paisagem por causa das estruturas turísticas, da dispersão do planejamento físico do desenvolvimento turístico e dos problemas econômicos, sociais e culturais.

No entanto, para que se possa ter um entendimento mais amplo sobre o real significado do turismo, faz-se necessário a compreensão dos conceitos de demanda e oferta turística. Segundo a OMT (2001), a demanda turística é composta pelo movimento de pessoas para lugares; viagens e estadas fora do ambiente normal de residência e trabalho; em um curto prazo de permanência.

Por outro lado, a oferta turística é composta por todos os serviços oferecidos aos visitantes (receptivos, alimentação, transporte, públicos, de recreação e entretenimento), representando um mix de atividades e setores que proporcionam uma experiência de viagem: estabelecimentos de hospedagem, alimentação, compras, e outros serviços de hospitalidade disponíveis (BENI, 2001).

Complementando essa visão, Oliveira (2000) subdivide a oferta turística em equipamentos e serviços turísticos e infraestrutura de apoio turístico; que compreende o sistema de comunicações, transportes e serviços urbanos. Os atrativos turísticos podem ser subdivididos em culturais (arquitetura, culinária, monumentos e museus), naturais (paisagem, parques e montanhas), eventos (festivais, eventos esportivos ou comunitários e feiras comerciais), lazer (passeios, trilhas e ciclismo) e entretenimento (parques temáticos, cinemas e comércio). (GOELDNER et al., 2002).

$\mathrm{O}$ aspecto fragmentado do setor evidencia a necessidade de uma coordenação e colaboração entre os participantes da oferta de um destino, sendo os fatores macro- 
ambientais (crise, concorrência, organization support e tecnologia) algumas das précondições para a formação de uma rede de turismo (WANG; FESENMAIE, 2007).

\section{REDES E TURISMO}

Os argumentos apresentados nessa seção têm como intuito possibilitar um entendimento do uso das estratégias de redes e outros tipos de alianças na tentativa de explicar as suas relações com o turismo e sua influência para o desenvolvimento regional.

Conforme Novelli et al. (2006) a aplicação dos conceitos de redes no turismo permite aos integrantes explorar sinergias e complementaridades em suas atividades, principalmente operando no nível das PME's. Para Xavier et al. (2011), a formação de uma rede turística poderá gerar benefícios e preservar valores e estilos de vida da comunidade, trazendo melhorias para a mesma.

No entanto, Martins et al. (2009) destacam a pouca quantidade de investigações que analisam a formação de redes aplicadas à prestação de serviços, principalmente quando comparado ao número de redes produtoras de bens tangíveis. Entretanto, mesmo diante da escassez de investigações, pode-se notar a existência de uma polarização das empresas prestadoras de serviços em torno de determinadas regiões, sendo algumas das associadas ao setor do turismo aquelas que mais apresentam ocorrências.

Procurando estabelecer uma conceituação sobre a aplicação dos conceitos de redes no turismo, a partir das análises feitas, torna-se viável definir uma rede turística como um grupo de agentes econômicos, políticos e sociais relacionados ao turismo, baseados num mesmo território, que se reúne para interagir, cooperar, aprender, trocar e obter inputs e outputs, de forma a garantir e conquistar mercados e promover inovação, competitividade e desenvolvimento.

Aprofundando sobre essa definição, Wang e Fesenmaie (2007) ressaltam algumas das pré-condições para a formação de uma rede de turismo, frisando os fatores macro-ambientais (crise, concorrência, organization support e tecnologia). Complementado sua visão, os mesmos destacam a crise como um dos principais influenciadores para a formação das alianças, considerando as parcerias como um meio eficaz de lidar com os diversos tipos de crise enfrentados em um destino. 
Sobre a influência dos fatores macro-ambientais e das crises, Wang e Fesenmaie (2007) destacam o ritmo acelerado dos movimentos econômicos e sociais, além das inovações técnicas desenvolvidas por outros destinos concorrentes, o que tem levado as empresas turísticas à necessidade de se adaptarem, para que consigam oferecer produtos capazes de atender às necessidades cada vez mais sofisticadas dos consumidores (turistas).

Para Novelli, Schmitz e Spencer (2006), essa sofisticação por parte dos consumidores, aliada à redução da permanência do turista nas localidades, constituem fatores cruciais para o baixo crescimento econômico de algumas cidades altamente dependentes da atividade turística. Esses fatores evidenciam a necessidade de consolidar, qualificar e ampliar a variedade de atrações e de facilidades destinadas ao turista como formas de expandir as oportunidades e reduzir a sazonalidade do setor, possibilitando o alcance de resultados satisfatórios, especialmente no que diz respeito ao gasto médio por pessoa, visitação dos municípios e dos atrativos, e ocupação de quartos.

$\mathrm{Na}$ busca por resultados satisfatórios no setor do turismo, a formação de redes estratégicas aparece como um dos mecanismos apropriados para atender aos desafios propostos pelo novo contexto de desenvolvimento regional, nos quais as redes de empresas prestadoras de serviços passam a ser consideradas como uma alternativa estratégica capaz de promover o desenvolvimento local. Essas redes se constituem em um conjunto de empresas e instituições dentro de um determinado espaço com o objetivo de aumentar a participação e desenvolvimento da região a partir das potencialidades locais e da articulação de diversos atores (BARRETO; OLIVEIRA; SICSÚ, 2007).

Segundo Martins et al. (2009), é através da articulação e da participação dos diversos atores locais, tanto de setores públicos como privados, que uma estratégia em rede poderá produzir uma potencialidade local a partir da atividade turística, passando a ter como preocupações a redução das diferenças sociais e a promoção do desenvolvimento regional.

A articulação entre diversos atores locais e a formação das redes estratégicas de cooperação entre empresas representa um papel importante na identidade regional (BERNARDES et al., 2006). O que leva à compreensão de que os habitantes de um 
lugar procuram incorporar ao seu próprio sistema cultural, os símbolos, valores e aspirações mais profundas da sua região (RUIZ et al., 2005).

Conectados em rede, cada ator é importante para o sucesso como um todo do turismo local e regional, devido à interdependência entre os diversos produtos e serviços que constituem uma rede estratégica de turismo. "Sem atrações e estabelecimentos de hospitalidade, geralmente não há uma localidade turística popular; sem uma localidade turística popular, pode não haver necessidade de um aeroporto; sem aeroporto, é menor a necessidade de um agente de viagem" (CHON, 2003, p. 28).

Ampliando essa visão acerca da interdependência dos atores locais na promoção do turismo, HALL (2005) resume da seguinte forma os fatores que levam ao desenvolvimento econômico local, através da associação em rede: a) redução das perdas através do uso sustentável dos recursos locais; b) aquisição de bens e produtos locais; c) agregação de valor aos produtos locais para poder exportá-los - marca própria e embalagem; d) estabelecimento de ligações entre as empresas locais - redes, alianças; e) atração de recursos externos - tecnologia, habilidades e recursos financeiros - e divulgação a clientes externos - através da Internet e e-mails; f) valorização da identidade local; g) contato direto com consumidores através de mala-direta, eventos locais e festivais; h) criação de uma relação duradoura consumidor/produtor.

Entretanto, para que a formação de redes proporcione o desenvolvimento local e regional, existe a necessidade pela transferência de conhecimentos e promoção da aprendizagem interna na rede, permitindo aos membros a compreensão sobre como os produtos e serviços turísticos poderão ser desenvolvidos e geridos. Essa necessidade se torna evidente a partir do momento no qual alguns membros têm a chance de conhecer as oportunidades disponíveis. Problemas esses são identificados no setor do turismo e hospitalidade quando estão relacionados à retenção de competências e à qualidade da cadeia de fornecedores locais (NOVELLI; SCHMITZ; SPENCER, 2006).

\section{PANORAMA DA PRODUÇÃO BIBLIOGRÁFICA INTERNACIONAL SOBRE REDES E TURISMO}

Essa seção tem o propósito de apresentar um panorama sobre a produção cientifica internacional envolvendo os temas redes e turismo. Para tal, realizou-se uma 
coleta dos dados na base de periódicos internacionais ISI Web of Science do índice de citações ISI Citation Indexes (THOMSON SCIENTIFIC, 2011), através de uma busca combinada entre os termos networks (redes) e tourism (turismo), no período de 2001 a 2010.

A base de dados utilizada foi impressa pela primeira vez na imprensa em 1963, com dados de citações a partir de 1961 (GARFIELD, 1963) e oferece acesso direto ao fluxo de informações multidisciplinar sobre cerca de nove mil periódicos internacionais de prestígio e fator de impacto para a pesquisa científica (THOMSON SCIENTIFIC, 2011).

Entre as 588 publicações encontradas na base de dados, observou-se que a grande maioria (aproximadamente 95\%) está em idioma inglês, sendo que nenhuma dessas foi escrita em idioma português. A partir dessa pesquisa, considerando o idioma predominante procurou-se identificar o número total de publicações por país dentro do período pesquisado, conforme se destaca no gráfico 1.

\section{GRÁFICO 1 - TOTAL DE PUBLICAÇÕES ENVOLVENDO REDES E TURISMO, POR PAÍS.}

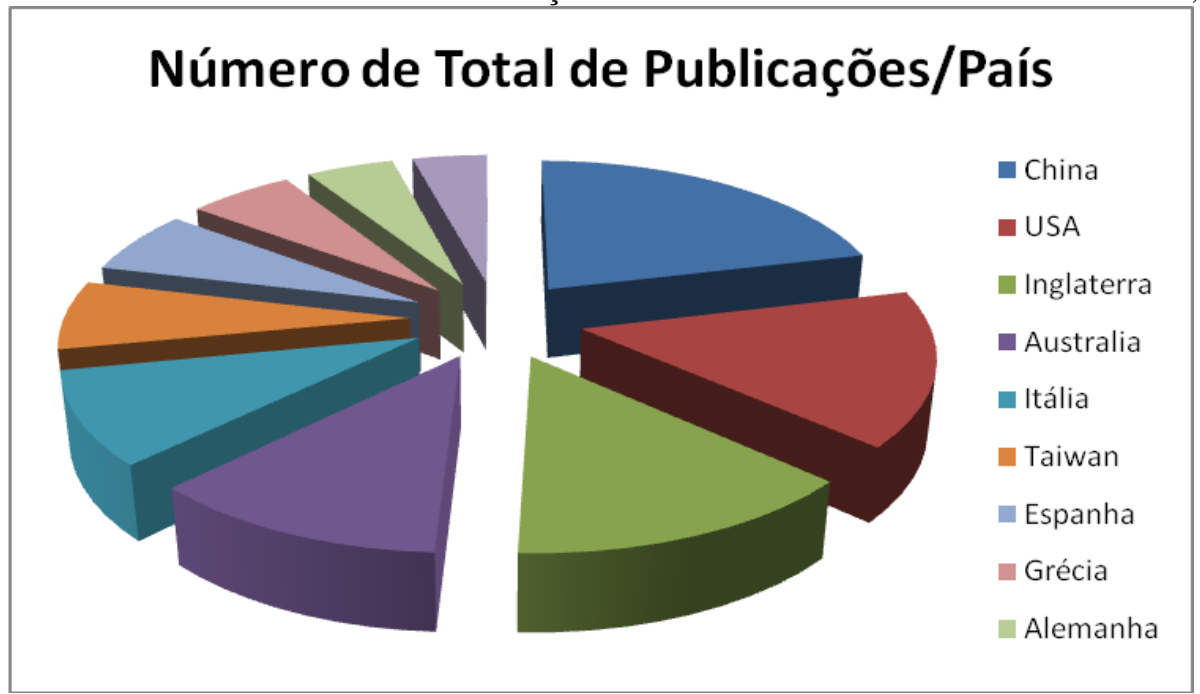

FONTE: ELABORADO PELOS AUTORES, A PARTIR DO BANCO DE DADOS DA ISI WEB OF SCIENCE (THOMSON SCIENTIFIC, 2011).

Analisando-se o gráfico 1 e os dados obtidos, tem-se a China como o país que mais publica trabalhos relacionando os temas redes e turismo (88), seguido pelos Estados Unidos (65), a Inglaterra (58), Austrália (49), Itália (39), Taiwan (29), Espanha (27), Grécia (24), Alemanha (20) e Canadá (17). O Brasil não aparece na lista dos países que mais publicam sobre os temas. 
Em seguida, observa-se o a evolução do número de publicações por ano, no período entre 2001 e 2010, conforme se demonstra no gráfico 2.

GRÁFICO 2 - TOTAL DE PUBLICAÇ̃̃ES SOBRE REDES E TURISMO, POR ANO.

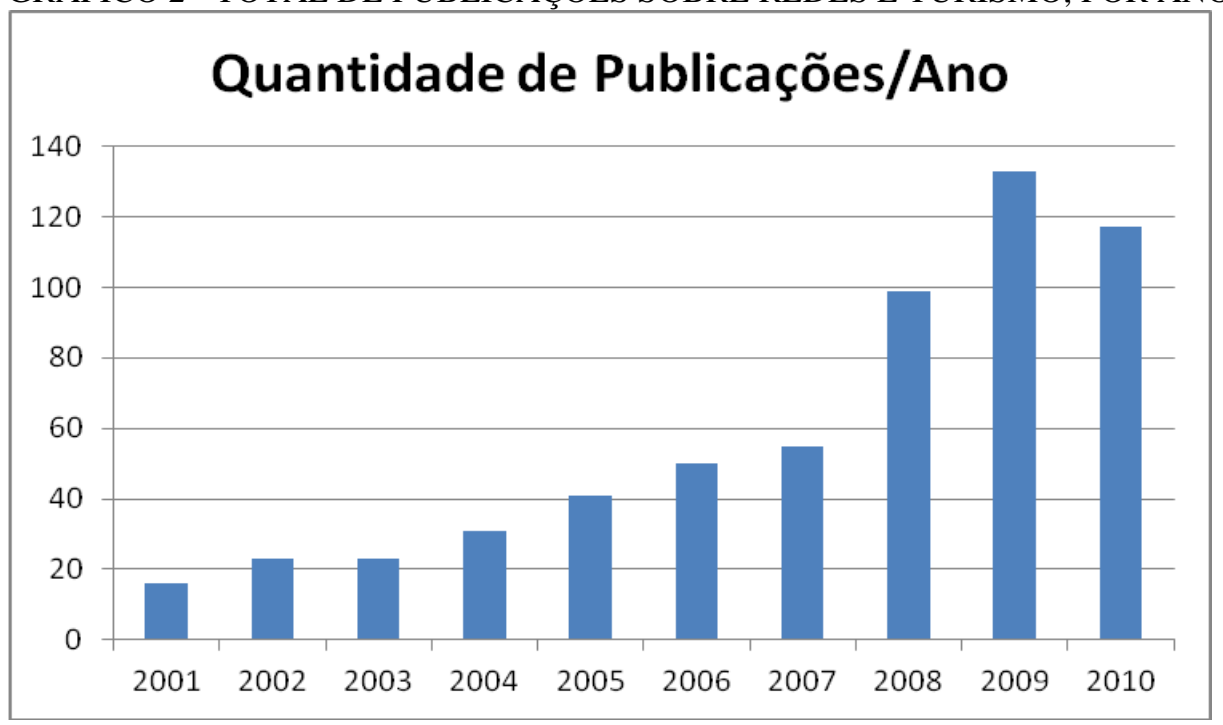

FONTE: ELABORADO PELOS AUTORES, A PARTIR DO BANCO DE DADOS DA ISI WEB OF SCIENCE (THOMSON SCIENTIFIC, 2011).

Os dados apresentados no gráfico 2 demonstram um crescente aumento no número de publicações a partir do ano de 2008, tendo a maior concentração em 2009.

Por fim, procurando averiguar a relevância dos estudos envolvendo a combinação das temáticas redes e turismo, foi realizada uma análise do número de vezes que cada publicação foi citada através do índice $h$ - $b$ e do índice $m$.

O índice $h$ - $b$ é apresentado por Banks (2010) como uma extensão do $h$-index, apresentado por Hirsch (2005) em sua pesquisa denominada "An index to quantify an individual's scientific research output", que tem como função quantificar o impacto e relevância da produção científica individual.

Essas contribuições fornecidas pelo h-index permitiram Banks (2010) a chegar ao índice $h-b$ que pode ser obtido através do número de citações de um tópico ou combinação em um período estabelecido, listados em ordem decrescente de citações. $\mathrm{O}$ índice $h$ - $b$ pode ser encontrado em publicações que tenham obtido um número de citações igual ou maior à sua posição no ranking.

Os estudos de Banks (2010) também apresentam e explicam o índice $m$ que é obtido através da divisão do índice $h-b$ pelo período de anos que se deseja obter 
informações $(n)$, que no caso desse trabalho é de 10 anos. Para análise do índice $m$ devem ser levadas em conta as seguintes considerações:

$\mathbf{0}<\mathbf{m} \leq \mathbf{0 , 5}$ : o tópico/combinação pode ser de interesse para pesquisadores em um campo específico de pesquisa, onde o campo engloba uma comunidade pequena;

$\mathbf{0 , 5}<\mathbf{m} \leq \mathbf{2}$ : o tópico/combinação provavelmente pode ser um "hot-topic" como área de pesquisa, onde a comunidade é muito grande ou o tópico/combinação apresenta características muito interessantes;

$\mathbf{m} \geq 2$ : é um tópico/combinação exclusivo, onde as conseqüêências têm um alcance não apenas na sua própria área de pesquisa. É provável que seja um tópico/combinação com efeitos de aplicação ou características únicas.

A partir dessas considerações obteve-se que o índice $\boldsymbol{h}$ - $\boldsymbol{b}$ das publicações envolvendo os temas redes e turismo é igual a $\mathbf{2 4}$, e que, consequentemente, o índice $\boldsymbol{m}$ é igual a 2,4 (quadro 2).

QUADRO 2 - ÍNDICE $H-B$ E ÍNDICE $M$ DAS PUBLICAÇÕES COMBINANDO OS TEMAS REDES E TURISMO

Índice $h-b$ \begin{tabular}{l|l|}
\hline Índice $m$ & 2,4 \\
\hline
\end{tabular}

FONTE: ELABORADO, A PARTIR DO BANCO DE DADOS DA ISI WEB OF SCIENCE (THOMSON SCIENTIFIC, 2011).

Os dados apresentados no quadro 2 mostram que as publicações internacionais envolvendo a temática redes e turismo caracterizam um hot-topic, sendo esta uma temática de crescente e relevante representatividade no cenário internacional no período $2001-2010$.

\section{CONSIDERAÇÕES FINAIS}

Considerando o objetivo proposto para o estudo, pode-se considerar que o mesmo foi alcançado, uma vez que a revisão de literatura proposta (seções 2, 3, 4 e 5) permitiu que fossem apresentados aspectos que permitem a compreensão das interconexões e complementaridade existentes entre os assuntos abordados.

Sobre esta consideração, compreende-se que a fragmentação inerente ao setor do turismo e a interdependência entre os mais variados bens e serviços (hospitalidade, transporte, hospedagem, alimentação, entretenimento, atrativos, públicos e urbanos) 
evidenciam a necessidade da formação de alianças entre os atores da rede turística do destino. Analogia que vai ao encontro às observações levantadas por Wang e Fesenmaie (2007), Martins et al. (2009), Flecha (2010), Inácio et al. (2012) e Xavier et al. (2011) de que a compreensão da relação e das influências que cada categoria de serviço oferece sobre o outro permite o entendimento sobre como os clusters turísticos podem auxiliar na qualificação da oferta turística e proporcionar o alcance de vantagens competitivas a um destino turístico.

Tais preceitos possibilitam visualizar a estrutura de uma rede de turismo como sendo baseada na informalidade, na qual as relações de interdependência e conexões entre os atores ocorrem, geralmente, de forma espontânea, não hierarquizada, autogeradora, sem a existência de uma forma de regulação. Tais fatores tornam a rede turística, na maioria dos casos invisível, cabendo ao gestor, observar, analisar e compreender as conexões existentes entre os atores, e buscar mecanismos que torne possível visualizar e coordenar essa correlação.

Consolidar, aumentar e qualificar as atrações e estruturas tem sido identificado como forma de expandir as oportunidades e reduzir a sazonalidade do setor, constituindo um desafio para os profissionais e gestores da área. Promover a cooperação entre os atores e a formar redes (clusters) de serviços turísticos estruturadas pode representar o caminho que possibilitará a uma localidade torna-se um destino turístico sustentável e rentável para os empresários, gestores e comunidade local.

Ao mesmo tempo, através das análises acerca das publicações envolvendo redes e turismo no período de 2001 - 2010 (seção 6) se pôde observar a predominância de artigos em língua inglesa, o que corrobora com o fato de países de mesmo idioma como Estados Unidos, Inglaterra e Austrália estarem nas primeiras colocações do ranking de publicações por país. No Entanto, embora a China lidere essa listagem, o mandarim não aparece entre os idiomas de maior destaque.

Outro aspecto relevante mostra que o número de publicações envolvendo a combinação dos temas encontra-se em progressivo aumento e que as mesmas possuem um alto fator de impacto, podendo ser consideradas um hot-topic.

Como limitações do estudo ressalta-se o fato de o mesmo se caracterizar, em suma, por uma discussão teórica sobre o tema. Restrição que faz emergir a relevância de que a partir da abordagem aqui exposta, se possa realizar estudos de natureza 
exploratória que visem aprofundar a compreensão acerca de quais categorias/variáveis (e como as mesmas se relacionam) inerentes ao tema redes precisam ser consideradas na análise das relações entre os atores que compõem a oferta em uma atividade turística.

\section{REFERÊNCIAS}

BANKS, M. G. An Extension of the Hirsch index: indexing scientific topics and compounds. Disponível em: <www.arxiv.org/abs/physics/0604216>. Acesso em: 07/07/2010.

BARRETO, R. R; OLIVEIRA, E. S; SICSÚ, A. B. Arranjo produtivo local e desenvolvimento endógeno: uma apresentação do APL de turismo no litoral norte do estado de Alagoas. In: XXVII ENCONTRO NACIONAL DE ENGENHARIA DE PRODUÇÃO, 2007. Anais... Foz do Iguaçu/PR, 2007.

BAUMAN, Z. Modernidade líquida. Rio de Janeiro: Jorge Zahar, 2001.

BENI, M. C. Análise estrutural do turismo. 6. ed. Editora Senac, São Paulo: 2001.

BERNARDES, A. T; ALBUQUERQUE, E; RUIZ, R. M; RIBEIRO, L. C. Modelling the role of national system of innovation in economical differentiation. In: 8TH GRANADA SEMINAR ON COMPUTATIONAL AND STATISTICAL PHYSICS (MODELING COOPERATIVE BEHAVIOR IN THE SOCIAL SCIENCES), 2005, Granada. Proceedings. New York: AIP, 2006.

CAPRA, F. A teia da vida: uma nova compreensão científica dos sistemas vivos. São Paulo: Cultrix/Amana-Key, 2001.

CARDOSO, L. A; PUSSIARELI, D. A. F. Subsídios à classificação de arranjos produtivos locais e distritos industriais. In: XIII Simpósio de Engenharia de Produção, 2006. Anais... Bauru/SP, 2006.

CASTELLS, M. A sociedade em rede: a era da informação, economia, sociedade e cultura. 4. ed. São Paulo: Impresso Brasil, 2000.

CHON, K. S. Hospitalidade: conceito e aplicações. São Paulo: Pioneira Thomson Learning, 2003.

COOPER, C; FLETCHER, J; WANHILL, S; GILBERT, D; SHEPHERD, R. Turismo: princípios e prática. Porto Alegre: Bookman, 2001.

DE SOUZA, M. Cooperação Inter-empresas e difusão das inovações organizacionais. SCTDE/FECAMP/UNICAMP-IE, Campinas, 1993. 
FLECHA, A. C. Alinhamento competitivo dos atores componentes de uma rede de turismo. Tese (Doutorado em Engenharia de Produção). Universidade Paulista, 2010.

FUKUYAMA, F. A grande ruptura: a natureza humana e a reconstituição da ordem social. Rio de Janeiro: Rocco, 2000.

FUSCO, J. P. A; BUOSI, G. R. C; RUBIATO, R. C. Modelo de redes simultâneas para avaliação competitiva de redes de empresas. Gestão \& Produção, v. 12, n. 2, p. 151163, maio-agosto, 2005.

GARFIELD, E. Science Citation Index. Science Citation Index 1961, v. 1, p. 5-16, 1963. Disponível em: <http://garfield.library.upenn.edu/papers/80.pdf〉. Acesso em: 28/06/2010.

HIRSCH, J. E. An index to quantify an individual's scientific research output. Proceedings of the National Academy of Sciences of the United States of America (PNAS), California, v. 102, n. 46, p. 16569-16572, 2005.

GOELDNER, C. R; RITCHIE, J. R. B; McINTOSH, R. W. Turismo: princípios, práticas e filosofias. 8. ed. Porto Alegre: Bookman, 2002.

GUERRINI, F. M. Taxonomia de formas organizacionais de produção a partir do recorte analítico de redes de empresas. In.: FUSCO, J. P. A. (org.). Redes produtivas e cadeias de fornecimento. São Paulo: Arte e Ciência Editora, 2005.

HALL, C. M. Rural wine and food tourism cluster network development. In: HALL, D.; KIRKPATRICK, I.; MITCHELL, M. (Eds.), Rural tourism and sustainable business, p.149-164, Clevendon: Channel View, 2005.

HASENCLEVER, L; KUPLER D. Economia industrial: fundamentos teóricos e práticas no brasil. Rio de Janeiro. Campus. 2002.

HUMPHREY, J.; SCHMITZ, H. Trust and inter-firm relations in developing and transition economies. IDS-University of Sussex, UK, 1998.

INACIO, R. O.; XAVIER, T. R.; FLECHA, A. C.; WITTMANN, M. L. Redes del turismo: La dinámica de las conexiones de la ciudad de Ouro Preto - Brasil. Estudios y Perspectivas en Turismo, Buenos Aires, v. 21, n. 2, p. 495-514, 2012.

LAZZARINI, S. G. Empresas em rede. São Paulo: Cengage Learning, 2008.

MARTELETO, R; DE OLIVEIRA E SILVA, A. Redes e capital social: o enfoque da informação para o desenvolvimento local. Ciência da Informação, Brasília/DF, v. 33, n. 3, p. 41-49, set./dez. 2004.

MARTINHO, C. Redes: uma introdução às dinâmicas da conectividade e da autoorganização. 1. ed. WWF-Brasil, 2003. 
MARTINS, D. A; NETO, P. M. S; SANTOS, E. M; ARAÚJO, G. H. A; CAMPOS, A. J. M. Arranjos produtivos locais: retrospectiva e tendências na perspectiva das operações de serviços. XVI SIMPÓSIO DE ENGENHARIA DE PRODUÇÃO, 2009. Anais... Bauru/SP, 2009.

NOVELLI, M; SCHMITZ, B; SPENCER, T. Networks, clusters and innovation in tourism: a UK experience. Tourism Management, v. 27, p. 1141-1152, 2006.

OLAVE, M. E. L; AMATO NETO, J. Redes de cooperação produtiva: uma estratégia de competitividade e sobrevivência para pequenas e médias empresas. Gestão \& Produção, v. 8, n. 3, p. 289-303, dez., 2005.

OLIVEIRA, A. P. Turismo e desenvolvimento: planejamento e organização. 2. ed. São Paulo: Atlas, 2000.

OLIVEIRA, M. F; TORKOMIAN, A. L. V. Aglomerações produtivas e internacionalização de pequenas empresas. Revista do Centro de Ciências Administrativas, v. 11, n. 1, p. 93-102, Fortaleza/CE, 2005.

OMT (Organização Mundial do Turismo). Introdução ao turismo. São Paulo: Roca, 2001.

PORTER, M. Clusters e competitividade. HSM Management, p. 100-110, Jul/Ago, 1999.

RUIZ, L. B.; BRAGA, T. R. M.; SILVA, F. A.; ASSUNÇÂO, H. P.; NOGUEIRA, J. M. S.; LOUREIRO, A. A. F. Uma abordagem de auto-gerenciamento para redes de sensores sem fio. In: XXIII SIMPÓSIO BRASILEIRO DE REDES DE COMPUTADORES, 2005. Anais... Fortaleza, 2005.

SANTOS, F; CROCCO, M; SIMÕES, R. Arranjos produtivos locais informais: uma análise de componentes principais para Nova Serrana e Ubá - Minas Gerais. Ensaios FEE, Porto Alegre, v. 24, n. 1, p. 177-202, 2003

THOMSON SCIENTIFIC. ISI Web of Science. Disponível em: <http://thomsonreuters.com/products_services/science/science_products/az/web_of_scie nce/>. Acesso em: 20/04/2011.

WANG, Y; FESENMAIE, D. R. Collaborative destination marketing: a case study of Elkhart County, Indiana. Tourism Management, v. 28, p. 863-875, jun./2007.

WITTMANN, M. L; VENTURINI, J. C; SCHMITT, P. A influência das redes empresariais na competitividade de micro e pequenas empresas. XXIV ENCONTRO NACIONAL DE ENGENHARIA DE PRODUÇÃO, 2004. Anais... Florianópolis/SC, 2004. 
XAVIER, T. R.; INACIO, R. O.; FLECHA, A. C.; WITTMANN, M. L. Solidez da oferta turística de um destino: um estudo sobre o Processo de seleção do turista acerca dos serviços turísticos no município de Ouro Preto/MG/Brasil. Turydes, Málaga, v. 4, n. 11, p. 1-17, 2011.

ZAGO, C. A; CAMFIELD, C. E. R; POLACINSKI, E; GODOY, L. P; WITTMANN, M. L. Redes Associativas como inovação organizacional: estudo de caso de uma rede supermercadista. Revista de Administração e Inovação, São Paulo, v. 4, n. 1, p. 5770, 2007.

Recebido em: 11-05-2012.

Aprovado em: 11-06-2102. 